\title{
Pricing and Revenue Management
}

\author{
By Mark Anthony Camilleri ${ }^{1}$, PhD (Edinburgh)
}

This is a pre-publication version of a chapter that was accepted by Springer Nature.

How to Cite: Camilleri, M. A. (2018). Pricing and Revenue Management. In Travel Marketing, Tourism Economics and the Airline Product (Chapter 9, pp. 155-163). Cham, Switzerland: Springer Nature.

\begin{abstract}
Modern revenue managers understand, anticipate, and react to market demand to maximise their businesses' revenues. They often do so by analysing, forecasting, and optimising their fixed, perishable inventory, and time-variable supply, through dynamic prices. Hence, the objective of pricing and revenue management is to stimulate demand from different customers to earn the maximum revenue from them. The essence of this discipline is to understand the customers' perceptions of value and to accurately align the right products to each customer segment. Therefore, this chapter suggests that revenue management systems combine data mining and operational research with strategy. Essentially, this involves maximising revenue from a combination of high-yield and price-sensitive customers; as these systems are intended to reduce seat spoilage and to increase load factors; thereby filling excess capacity. Moreover, these systems also manage overbookings, and are intended to minimise denied boarding.
\end{abstract}

\subsection{Introduction}

The role of pricing and revenue management systems is to optimise the product for different kinds of customers. Pricing and revenue managers use data-driven, yield management systems to allocate adequate and sufficient capacity to profitable customers. At the same time, they also

\footnotetext{
${ }^{1}$ Department of Corporate Communication, Faculty of Media and Knowledge Sciences, University of Malta, Malta. Email: mark.a.camilleri@um.edu.mt
} 
meet the needs of price-sensitive customers. Hence, customer-centric, yield management systems forecast demand and availability, to maximise revenue by using differentiated prices, at the right time. Such price optimisation strategies suit each individual customer. For instance, the purpose of the airline revenue management systems is to optimise the passenger mix on each flight. In this light, this chapter explains the concept of yield management. It sheds light on the various factors which influence the pricing of travel products to different customers.

\subsection{Defining Yield Management}

Yield management is a variable-pricing strategy which anticipates and influences consumer behaviour. It is intended to maximise revenue and profits from a fixed, time-limited resource (such as airline seats or hotel rooms). Pricing, revenue and yield management systems will support travel and tourism businesses as they sell products to the right customer, at the right time, for the right price. Very often, the yield management processes could result in price discrimination, as customers who are consuming identical goods or services are usually charged different prices.

As the customers demand for seamless, personalised travel experiences, airlines and many hotels are increasingly implementing pricing strategies that are aligned with their revenue objectives. Their revenue management systems provide accurate, real-time information in the right format (Chase, 2007). They will enable them to improve their retailing, whilst responding to the shifting market dynamics (Talluri, 1999). At the same time, yield management systems could help businesses to maintain and expand their market share, and to increase their profits, on a day-to-day basis (Cross, 1997).

Yield controllers use highly-sophisticated computer systems to forecast the consumers' behaviours (Chase, 2007). Specifically, they could identify when customers purchase certain products, and determine at what prices they are purchasing them. This allows businesses to protect enough space for late booking, high-yield passengers or guests, whilst at the same time, allocating the remaining space to discount fares. Effective yield management systems provide differentiated fares to meet the needs, wants and expectations of different customers; whilst simultaneously ensuring that the business gets the highest possible revenues from each and 
every customer. Hence, yield management involves; setting differential pricing, as well as adopting non-pricing strategies, including overbooking management.

\subsection{Differential Pricing}

The raising or lowering of the price is the most basic task of a revenue manager. At times, the higher prices may usually result in fewer bookings. However, if there is adequate and sufficient demand, the setting of a high price could result in profitable business transactions with highyield customers. Very often, businesses may use specific marketing communications to target affluent customers. Conversely, a decrease in price could easily generate demand from pricesensitive customers. Therefore, yielding may also involve turning away less attractive customers. To do this, businesses could resort to tactics, such as; introducing restrictions, utilising particular marketing channels, et cetera. For example, setting a minimum length of stay (for a hotel accommodation) is one way of achieving this objective. Adding or removing inventory for a channel, is another option.

\subsection{Fare (Seat) Mix Management}

The correct implementation of the yield management systems could improve the airlines' revenue, whilst enabling them to better meet the needs of their marketplace (Belobaba, 1987). Yield management increases the possibility of seats being available to profitable, late booking business travellers. The airline product could also be aimed at price-sensitive customers, as revenue management systems allow for a wider variety of discounts, particularly to advance purchasers. The lower fares have the effect of both stimulating demand, and filling excess capacity; without decreasing unit revenue. Yield management systems use dynamic pricing that is based on current demand in order to optimise the passenger mix on each and every departure; so that the revenue on each flight is maximised.

Consequently, a broad range of fares will usually target different customer segments. For instance, an airline sells 100 seats for $\$ 50$ and generates $\$ 5,000$. However, if it offers four fares of $\$ 80, \$ 60, \$ 40$ and $\$ 20$ and it sells 25 seats at each fare, it generates the same figure. However, in the latter case, there are both high yield customers, as well as price-sensitive customers who 
are travelling with the airline. An increase in the number of high-yield fare passengers will increase the profitability of the airline. However, if an airline will only provide high fares, eventually, it would lose some lower fare customers. Either passengers would be driven to buying from lower-priced competitors; or they would be driven completely out of the market. Therefore, airlines need to find a satisfactory balance between yield and load factor. Such a trade-off is extremely difficult to create, as every single flight has its own individual booking pattern.

The technical definition of 'yield' is; revenue per revenue passenger kilometre. This can be calculated from the net fare (after discounts and commissions), which is divided by the number of kilometres flown. For example: When the fare is $\$ 200$ and the distance is 800 kilometres; the yield is $200 / 800=\$ 0.25$ per kilometre. This can also be defined as; 'an amount yielded' (i.e. the return of a financial investment, usually calculated with reference to the cost and dividend).

\subsection{Non-pricing Strategies}

Frequently, travel businesses will have no-shows. No shows are those customers who make reservations, but fail to honour them. Similarly, there may be airline passengers who book seats on specific flights, and then will fail to turn up. For this reason, aircraft may sometimes takeoff with empty seats. For this reason, businesses use overbooking and other review strategies to minimise costs, whilst mitigating customer impact.

\subsubsection{Airline Overbooking}

In the airline industry, as in any other, it is very important to exercise control over the variables which affect revenues. Customarily, the airlines' flights are loaded with a precise number of seats that are allocated to each fare or class of service. However, in an effort to reduce and minimise the cost of spoilage (empty seats), several airlines deliberately overbook their flights. Their effective capacity management systems will also enable them to set an acceptable overbooking level. Yet, the airlines' overbookings may increase the risk of denied boardings; which may be detrimental to the airlines' image and reputation. Both the denied boardings and the no-shows will result in significant financial losses to the airlines concerned. 
The costs of the spoiled seats (from an airline's perishable service) can be calculated by multiplying the number of empty seats by the average fare. However, the cost of denied boarding is harder to quantify, as this involves handling dissatisfied customers, who may easily churn for other carriers. Hence, the yield management systems should be designed to minimise these contingent issues.

Hence, the overselling of any flight is a process which must be handled very delicately, as different variables must be taken into account, including; time of departure, route, day of the week, fare mix, seasonality and historic flown data. The fundamental concept behind overbooking is to maximise revenue opportunities, by limiting seat spoilage, whilst striving to reduce any denied boarding.

\subsection{Integrating Yield Management}

Although, yield managers may usually have access to elaborate systems that could provide them with insightful data about customers; they would also benefit from effective communication with their colleagues, from reservations; pricing, sales and check-in departments, among others.

Reservations and sales staff are the airline's front-liners. They regularly deal with prospective customers. For this reason, they are in a good position to provide valuable information to yield managers. Conversely, yield managers can also exchange useful feedback with them. For instance, they can inform them on special offers that may be targeted at particular travellers. Certain flights may be suitable for the price-sensitive, leisure customers.

Pricing and yield management (very often they are the same department) could identify high load-factor markets. Certain destinations may provide an opportunity to increase fares. Alternatively, pricing managers may need to stimulate demand by decreasing fares in low loadfactor markets.

Based on the relevant information that is provided by yield controllers, sales managers can design programmes which could create new business opportunities for the airline. They can do this without causing revenue dilution; that is often created by the displacement of high-yield 
traffic. Sales and yield management could possibly direct group bookings toward certain flights and routes, to increase more traffic.

The yield management department should also collaborate with the passenger services department, particularly with the check-in staff who will often have to deal with denied boardings, due to overbooked flights. Moreover, check-in staff may possess essential 'flown' information (this is information on no-shows and go-shows) which may be useful to the yield managers (although they may already possess this information through their revenue management systems). However, it would be beneficial for the airline; if the departments communicate on a regular basis, particularly about over-sales levels and denied boardings. From a financial perspective, the airline will improve its operations if the number of spoiled seats is reduced and the risk of denied boarding is minimised.

\subsection{Customer-Centric Yield Management}

Marketing managers use pricing, revenue and yield management systems to identify their customers' requirements, and their booking behaviours. In essence, there are two basic types of passengers - business and leisure passengers. They differ in terms of their needs, wants and expectations. The passengers' unique requirements will dictate their booking characteristics, including: when they book their seats; how much they are willing to pay; how likely they are to no-show; which airline they choose to fly with; where they stay; et cetera.

We have already seen how yield management can be extremely beneficial to an airline when it is implemented in a correct manner. However, these systems are also intended to improve the customers' experience. For the business passengers, a yield management system would ensure that more seats are available for last minute bookings. Moreover, it would also cater to the leisure market by offering low fares to advance purchase customers.

\subsubsection{The Business Passengers' Requirements}

The business passengers will usually purchase their flights very close to the date of their departure. Therefore, they would expect the airlines to provide available seats at the latest possible time. These customers may need to fly at very short notice. At times, they may also have to change their flights, or to cancel their itinerary. Generally, the cost of the ticket will be 
less important to these travellers, than the time and date of departure. Therefore, business customers will usually avail themselves of flexible, high fares which will allow them to book at the very last minute. These customers are charged the highest fares. Therefore, this segment will provide the higher yields to the airline. As business passengers are willing to pay the highest fares, they are extremely profitable to airlines. The pricing, revenue and yield managers must ensure that these passengers' expectations are always satisfied.

\subsubsection{The Leisure Passengers' Requirements}

The booking patterns of leisure passengers are completely different than those of the business passengers. Unlike the business passengers, who usually book very close to the departure date; the leisure passengers may book well in advance. In this case, the time and date of departure may be considered less important factors to the leisure passengers.

\subsection{Revenue Management Mechanisms}

Since the business and economy class passengers have different purchasing behaviours, revenue management systems strive to create a balance between these distinct groups of customers. This may prove challenging to the airlines' yield managers. The reason for this lies in the fact that the demand for discounted fares, will usually occur before there is the demand for the higher fares. As both passenger groups are competing for the 'same' seat, it is up to the yield controller to decide to whom the seat must be allocated. A fundamental task of yield management is to find a trade-off among full fare (business) passengers and the various other discount passengers (Smith, Leimkuhler \& Darrow, 1992; Belobaba, 1987). If this balance is achieved, the airlines will be in a position to satisfy all of their passengers' needs, while simultaneously maximising their yield.

If the airlines quote a low-yield price for their seats, they will sell them well in advance of their flight departure dates. In this case, it would be likely that most of the customer bookings will be mostly from leisure passengers. Therefore, there won't be seats available for sale when business passengers contact the airline, at a later stage. This issue may lead the business persons to travel with one of the airlines' competitors (assuming that a seat is available with them). If 
the business travellers are consistently refused last-minute bookings with any airlines, they will stop trying to fly with them.

The airlines' yield management systems control when capacity is made available for sale. These data-driven systems will usually involve the blocking of seats to high-yield passengers. This capacity will be released prior to the departure date. Higher prices will be charged to passengers as the departure date approaches. It is very likely that these seats will be purchased by the business travellers who will usually book late, at very high prices (Swarbrooke, \& Horner, 2001).

Whilst the former approach ensures that the airlines' flights are filled with low yield passengers. The latter approach offers greater opportunities to sell more seats at high yield fares. At the same time, it is equally possible that high yield seats could remain unsold. This could result in a loss of revenue.

In sum, elaborate revenue management systems are capable of providing a high degree of accuracy, as they are based on previous booking patterns (Chase, 2007). Therefore, yield controllers are increasingly relying on advanced digital technologies to price their seats to different consumer segments.

\subsection{The Essential Criteria for Successful Yield Management}

\subsubsection{Personnel}

A successful yield management programme requires dedicated and competent employees that are experts on their airline's route network, competitors' destinations, schedules, prices, as well as on consumer demand (Smith et al., 1992; Belobaba, 1987).

\subsubsection{Data-driven Systems}

The yield controllers necessitate up-to-date information on their external marketing environment and on their companies' capabilities, resources and competences. Moreover, the management of data and analytics will support them in their strategic decision making and dayto-day operations. Very often, revenue management systems will provide them with detailed 
information on past transactions, which will clearly indicate the number of (un)sold seats (and waitlisted passengers, et cetera) for specific flights, during the day, week or other periods. They may also anticipate the booking patterns into the future. These systems usually indicate when and where there is demand for certain destinations. They could specify which flights may be sold quicker than others; as they reveal how many bookings have been received, to date. They may be used to analyse booking patterns, by comparing data with previous periods. They could also report past punctuality records, no-shows, go-shows and denied-boarding, among other metrics.

The pricing, revenue and yield management systems would typically consist of the following elements:

i. The Yield Management System: This involves drawing information from the airline's reservation system This data could be used to extract reports on advance bookings;

ii. Historic Bookings: This is information on the airline's full booking history for the past months or years. It could include forecasts that are based on past records;

iii. Flown Data: This is relevant information on past flights, including; no-shows and goshows;

iv. The Reservation System: An airline's reservation system will usually hold inventory flights into the future as well as booking records of past itineraries. The reservation systems are used by yield controllers to load the schedule with specific seat allocations for a full season, and to make changes to the airline's inventory on a day-to-day basis;

v. Culture: The organisations' different departments must support the yield managers. An organisational culture which fosters a collaborative environment among members of staff would improve the objectives of yield management. For example, the yield managers could hold relevant data which could assist the check-in staff in dealing with displaced passengers, particularly during the high season when there are more travellers. The members of staff should recognise the importance of having a total quality management mantra. Effective engagement across departments would help the airline to improve the customers' overall experience with the airline. 


\subsection{Questions}

- Yield management can be defined as: 'the process which matches demand and supply, to earn the maximum revenue on each and every flight'. How is this match actually achieved?

- What is the reason for the widespread practice of overbooking within the airline industry?

- Define (i) the cost of a spoiled seat and (ii) the cost of denied boarding.

- Business passengers and leisure passenger have different booking characteristics. Briefly outline the booking pattern of both passenger groups.

\subsection{Summary}

Yield management can be defined as the process that is used to match demand and supply; to earn the maximum revenue on each and every flight. Its underlying objective is to optimise the passenger mix on each departure. In the airline industry, the technical definition of the term 'yield' is revenue per revenue passenger kilometre. This can be calculated from the net fare (after discounts and commissions) divided by the number of kilometres flown. It can also be defined as the yielded amount.

Yield management increases the possibility of seats being available for high yield, late booking passengers. It also involves the allocation of seats to lower discount fares. This has the effect of both stimulating demand and filling excess capacity, without decreasing revenues by any significant amount. Revenue management systems could reduce unanticipated denied boardings, while at the same time, increasing load factors. This can be achieved by managing differential pricing or overbooking practices. An effective overbooking management could reduce seat spoilage.

Yield management systems can make a substantial difference to an airline's profits. Therefore, it is imperative that the entire airline is committed and dedicated to it, including the reservations, pricing, sales and check-in employees, among others. Some of the essential criteria for successful yield management include; the airlines' (or hotels') personnel and data driven systems. 
